\title{
Effect of deoxycholic acid and ursodeoxycholic acid on lipid peroxidation in cultured macrophages
}

\author{
P Ljubuncic, B Fuhrman, J Oiknine, M Aviram, A Bomzon
}

\begin{abstract}
Background-Kupffer cells are essential for normal hepatic homeostasis and when stimulated, they secrete reactive oxygen species, nitric oxide, eicosanoids, and cytokines. Some of these products are cytotoxic and attack nucleic acids, thiol proteins, or membrane lipids causing lipid peroxidation. Hydrophobic bile acids, such as deoxycholic acid (DCA), can damage hepatocytes by solubilising membranes and impairing mitochondrial function, as well as increasing the generation of reactive oxygen species.

Objectives-The hypothesis that hydrophobic bile acids could stimulate Kupffer cells to increase their capacity to generate reactive oxygen species by measuring cellular lipid peroxidation was tested. Because the hydrophilic bile acid, ursodeoxycholic acid (UDCA) can block hydrophobic bile acid induced cellular phenomena, it was also hypothesised that UDCA could antagonise macrophage activation by hydrophobic bile acids to blunt their capacity to generate reactive oxygen species. Methods-J-774A.1 murine macrophages were incubated for 24 hours with either $10^{-5} M$ and $10^{-4} M$ (final concentration) DCA alone, or $10^{-4} M$ UDCA alone, or a mixture of $10^{-4} \mathrm{M}$ 1:1 molar ratio of DCA and UDCA. At the end of the incubation period, the culture medium was collected for determination of cellular lipid peroxidation by measuring the malondialdehyde (MDA) content in the medium with the thiobarbituric acid reactive substances assay.
\end{abstract}

Results $-10^{-5} \mathrm{M}$ and $10^{-4} \mathrm{M}$ DCA increased MDA generation by cultured macrophages. $10^{-4} M$ UDCA alone did not increase MDA generation but blocked the peroxidative actions of DCA.

Conclusions-Hydrophobic bile acids, after their hepatic retention, can oxidatively activate Kupffer cells to generate reactive oxygen species. Because UDCA can block this action, the beneficial effect of UDCA is, in part, related to its ability to act as an antioxidant.

(Gut 1996; 39: 475-478)

Keywords: macrophages, deoxycholic acid, ursodeoxycholic acid, antioxidant.

Hepatic macrophages or Kupffer cells are essential for normal hepatic homeostasis. ${ }^{1}$
When hepatic homeostasis is potentially jeopardised, as in viral hepatitis, or by circulating endogenous compounds (endotoxin and $\mathrm{T}$ cell lymphokines) or xenobiotics (alcohol, acetaminophen, and $\gamma$ interferon), Kupffer cells are activated to increase their capacity to generate reactive oxygen species, nitric oxide, eicosanoids, and cytokines as part of the universal inflammatory response. ${ }^{2}$ Some of these products are cytotoxic, such as reactive oxygen species, which attack nucleic acids, thiol proteins, or membrane lipids causing lipid peroxidation. ${ }^{34}$ Reactive oxygen species can also react with nitric oxide to generate peroxynitrite and singlet oxygen, both of which are cytotoxic. ${ }^{56}$

Extracellular and intracellular retention of bile acids, associated with cholestatic liver diseases, injures hepatocytes. ${ }^{7}$ Hydrophobic bile acids, such as chenodeoxycholic acid and deoxycholic acid (DCA) at millimolar concentrations, can solubilise membranes by promoting the loss of cholesterol and phospholipids ${ }^{8}$ or can cause membrane damage by activating phospholipase $A$ and the generation of reactive oxygen species. ${ }^{9}$ Data from several laboratories have also shown that these same hydrophobic bile acids, at micromolar concentrations, are mitochondrial toxins leading to ATP depletion ${ }^{10}$ and causing permeability transition of mitochondrial membranes. ${ }^{11}$ Hydrophobic bile acid toxicity may be linked to increased generation of reactive oxygen species. ${ }^{10} 12$ It is also known that hydrophilic ursodeoxycholic acid (UDCA) can antagonise these effects ${ }^{13-16}$; and these mechanisms have been suggested as the basis for the beneficial effects of UDCA in patients with cholestatic liver disease. ${ }^{17-24}$

Although many of the stimuli for activating Kupffer cells have been identified, the effect of bile acids on their activity has not been fully investigated. In the light of our existing knowledge on bile acid induced hepatocyte injury and the possible involvement of reactive oxygen species in the pathogenesis of cholestatic liver diseases, we hypothesised that hydrophobic bile acids could stimulate Kupffer cells to increase their capacity to generate reactive oxygen species. Because UDCA can block hydrophobic bile acid induced cellular phenomena, we also hypothesised that UDCA could antagonise macrophage activation by hydrophobic bile acids to blunt their capacity to generate reactive oxygen species. This study reports our experimental findings in which we tested these hypotheses by assessing the effects of hydrophobic DCA and hydrophilic UDCA 
on cultured macrophages by measuring their cell lipid peroxidation.

\section{Methods}

Materials

Culture medium RPMI-1640, streptomycin, penicillin, phosphate buffered saline (PBS), and fetal calf serum (FCS) were all purchased from Biological Industries (Beth Haemek, Israel). Bovine serum albumin (BSA), thiobarbituric acid (TBA), and DCA were all purchased from Sigma Chemical Co (St Louis, MO, USA). UDCA was purchased from Calbiochem (La Jolla, CA, USA).

Cells

J-774A.1 murine macrophage-like cell line was obtained from the American Tissue Culture Collection (Rockville, MD, USA). The cells were maintained in culture in RPMI-164 medium without phenol red (to eliminate the interference of the medium colour with the production of the pink chromophore during the determination of cellular lipid peroxidation (see later for details)) supplemented with 100 $\mathrm{U} / \mathrm{ml}$ penicillin, $100 \mu \mathrm{g} / \mathrm{ml}$ streptomycin, and $5 \%$ heat inactivated $\left(56^{\circ} \mathrm{C}\right.$ for 30 minutes) FCS. This medium did not contain added iron ions or other transition metals. The cells were plated at $5 \times 10^{5}$ cells per $35 \mathrm{~mm}$ multiwell dishes, and were fed every three days.

\section{Measurement of cellular lipid peroxidation and the effect of bile acids}

The determination of cellular lipid peroxidation was similar to the method previously described by us. ${ }^{25}$ Briefly, cells were incubated for 24 hours in RPMI-1640 medium containing $0 \cdot 2 \% \mathrm{BSA}$ in the absence (control) and presence of either $10^{-5} \mathrm{M}$ and $10^{-4} \mathrm{M}$ (final concentration) DCA alone, or $10^{-4} \mathrm{M}$ UDCA alone, or a mixture of $10^{-4} \mathrm{M}$ 1:1 molar ratio of DCA and UDCA. At the end of the incubation period, the culture medium was collected for analysis of the malondialdehyde (MDA) content by the thiobarbituric acid reactive substances (TBARS) assay. ${ }^{26}$ The TBARS assay measures the amount of MDA, an end product of peroxidative decomposition of polyeonic fatty acids, and is widely used as a screening assay to quantify the extent of lipid peroxidation in vitro. ${ }^{27}$ We have previously shown that MDA produced by macrophages is almost completely secreted into the medium. ${ }^{25}$ To exclude possible bile acid-thiobarbituric acid reactions, the TBARS assay was performed with bile acids alone; TBARS were not generated. The cell protein content was determined by the method of Lowry et $a l^{28}$ after the cells were lysed with $0 \cdot 1 \mathrm{~N} \mathrm{NaOH}$.

\section{Statistical analysis of the data}

Each experiment was repeated three times and analysed by one way ANOVA. A p $<0.05$ (two tailed) was considered significant.

\section{Results}

Incubation of J-774.1 macrophages in subconfluent culture with $10^{-5} \mathrm{M} \mathrm{DCA}$ and $10^{-4} \mathrm{M}$ DCA, alone for 24 hours at $37^{\circ} \mathrm{C}$ significantly increased the MDA content in the medium from a control value (mean (SD)), $0.74(0.12)$ $\mathrm{nmol} \mathrm{MDA} / \mathrm{mg}$ cell protein, to $1.70(0.07)$ $\mathrm{nmol} \mathrm{MDA} / \mathrm{mg}$ cell protein $(\mathrm{p}<0.01)$ and 1.29 $(0.08) \mathrm{nmol} \mathrm{MDA} / \mathrm{mg}$ cell protein, respectively, $\left(p<0.05\right.$; Figure). Incubation with $10^{-4}$ $M$ UDCA alone did not increase MDA content $(0.77$ (SD 0.07$) \mathrm{nmol} \mathrm{MDA} / \mathrm{mg}$ cell protein), a value almost identical to the control (Figure). When the cells were incubated with $10^{-4} \mathrm{M}$ DCA and $10^{-4} \mathrm{M}$ UDCA, at a $1: 1$ molar ratio, the MDA content $(0.70$ (SD 0.09) $\mathrm{nmol} \mathrm{MDA} / \mathrm{mg}$ cell protein) was also not significantly different from the control or from the value when UDCA alone was added (Figure).

The cell protein content of the cultured macrophages exposed to bile acids was not different from the control indicating that cell viability was preserved after 24 hours of exposure to bile acids.

\section{Discussion}

\section{Methodological considerations}

Before discussing the data, some comments on the concentrations and the possible toxicity of bile acids used in these experiments are necessary. In liver tissue of patients with cholestatic liver disease, such as primary biliary cirrhosis, the intrahepatic concentration of total bile acids can rise as high as $600 \mathrm{nmol} / \mathrm{g}$ liver tissue $^{29}$ and is largely due to the accumulation of the hydrophobic bile acids, chenodeoxycholic acid, and DCA. ${ }^{30}$ In our experiments, the cultured macrophages were incubated with $10^{-5} \mathrm{M}$ and $10^{-4} \mathrm{M}$ DCA. Assuming that $1 \mathrm{~g}$ liver is equivalent to $1 \mathrm{ml}$, these concentrations approximate to the hydrophobic bile acid concentrations found in cholestatic livers.

The total fasting serum bile acid concentration (normally $<10 \mu \mathrm{M}$ ), rises to reach

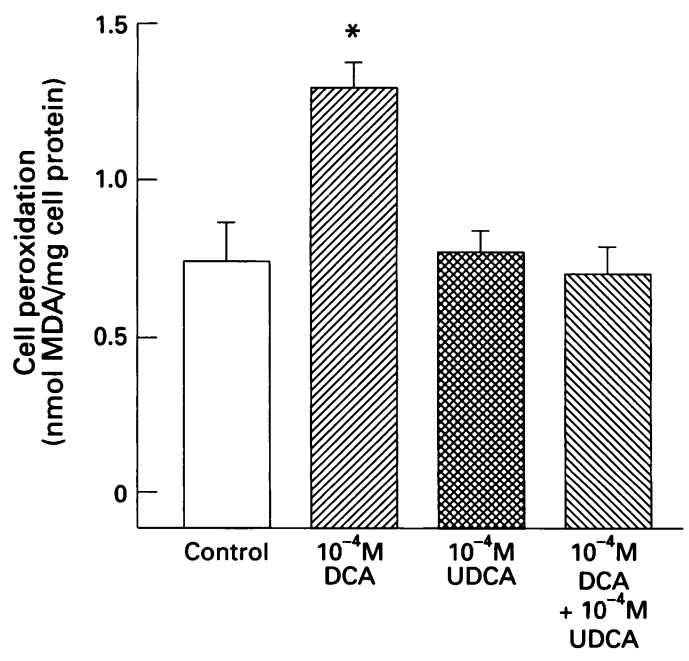

Effects of $10^{-4} \mathrm{M} D C A, 10^{-4} \mathrm{UDCA}$, and $10^{-4} \mathrm{M} D C A$ and UDCA (1:1 molar ratio) on cultured macrophage cell peroxidation measured by MDA content in the collected culture medium. For each experiment $n=3 .{ }^{p}<0.05 \mathrm{v}$ control. 
values as high as $200 \mu \mathrm{M}$ in patients with cholestatic liver disease. ${ }^{31}$ When these patients are treated with UDCA at the usual dose of about $10 \mathrm{mg} / \mathrm{kg} /$ day (750-1000 mg/day), liver function improves. This beneficial effect is associated with further increases in the total fasting bile acid concentration and changes in the serum bile acid profile with the plasma UDCA concentration reaching around 90 $\mu \mathrm{M} / .^{21}{ }^{32}$ This concentration of UDCA determined the choice of the concentration of UDCA in our experiment.

For these experiments, we have relied on total cell protein as a measure of cell viability and function. Previously, we have shown that the correlation between this index and other indices of cell viability is high indicating that the concentrations of DCA were not toxic to the cultured macrophages. ${ }^{25}$

\section{Effect of deoxycholic acid on lipid peroxidation in macrophages}

This study has shown that DCA at a concentration below its critical micelle concentration can increase the level of cellular lipid peroxidation, one of the consequences of increased production of reactive oxygen species. We have interpreted this result to suggest that hydrophobic bile acids, after their hepatic retention, can oxidatively stimulate Kupffer cells to generate reactive oxygen species in vivo. This suggests that bile acids may also damage hepatocytes by an indirect pathway mediated by increased generation of reactive oxygen species by hydrophobic bile acid stimulation of Kupffer cells. Sokol et $a l^{12}$ have shown that hydrophobic bile acids can also stimulate the generation of reactive oxygen species in hepatocytes. Given this additional information, our data also indicate that hydrophobic bile acids can affect both the hepatocyte and Kupffer cells to generate reactive oxygen species and raise the level of oxidative stress in cholestatic liver disease.

\section{Effect of ursodeoxycholic acid on lipid peroxidation} in macrophages

UDCA has been used with considerable success in the treatment of chronic liver disease. ${ }^{13-16}$ The manner in which UDCA improves liver function is apparently diverse and several mechanisms have been proposed. Therapeutic dosing concentrations of UDCA enrich the bile acid pool with UDCA and, in doing so, shift the pool profile from one of hydrophobicity to hydrophilicity. ${ }^{32-35}$ Consequently, toxic hydrophobic bile acids are displaced by UDCA to the extent that UDCA becomes the major circulating bile acid. ${ }^{33}$ As much of the hepatic damage is caused by the endogenous hydrophobic bile acids, it has been suggested that UDCA may prevent or reduce hydrophobic bile acid damage itself ${ }^{836}{ }^{37}$; and by virtue of displacement of the hydrophobic bile acids with UDCA, this may be the operative mechanism by providing cytoprotection of the hepatocyte. Secondly, UDCA can increase transcellular and canalicular transport of the bile acids thus reducing the hepatic retention of hydrophobic bile acids in patients, ${ }^{38}$ as well as inducing a bicarbonate rich hypercholerosis in rats and hamsters. ${ }^{39} 41$ Thirdly, UDCA can reduce the level of hepatic expression of human leucocyte antigen, lower serum IgM concentrations, and reduce mononuclear cell production of IgG, IgA, IgM, and cytokines, ${ }^{42}$ as well as interfering with cell surface receptors or signalling systems of immunologically active cells. ${ }^{43}$ Consequently, these immunomodulatory properties of UDCA are also considered an integral mechanism of its ameliorative actions in patients with primary biliary cirrhosis. The beneficial action of UDCA has also been attributed to its ability to change the physicochemical properties of cell membranes by creating a membrane 'barrier' and thus stabilising membrane structure and preventing its disruption by toxic bile acids. ${ }^{836}{ }^{44}$ UDCA can also block the metabolic depressant effects of hydrophobic bile acids on hepatocyte mitochondrial function. ${ }^{14} 16$

This study has shown that the peroxidative effect of hydrophobic bile acids, such as DCA, on cultured macrophages can be blocked by UDCA, which itself has no oxidative properties on cultured macrophages when used at therapeutic plasma concentrations. We have interpreted this result to suggest that the beneficial effect of UDCA may be related to its ability to prevent hydrophobic bile acid induced macrophage oxidative stimulation. Thus we suggest that UDCA has antioxidant properties that can also contribute to its advantageous action in patients with cholestatic liver disease. Moreover, it is also tempting to speculate that UDCA may suppress Kupffer cell peroxidation, irrespective of the activating factor. This 'dampening' effect on macrophages may also explain the beneficial immunomodulatory properties of UDCA. ${ }^{42} 43$

This project was supported by a grant from the Ministry of Science and Arts, Jerusalem, Israel. PL is an immigrant scientist supported by a grant from the Ministry of Immigration and Absorption, Jerusalem, Israel.

1 Johnston RBJ. Monocytes and macrophages. $N$ Engl $\mathcal{F}$ Med 1988; 318: 747-52

2 Rosser BG, Gores GJ. Liver cell necrosis: Cellular mechanisms and clinical implications. Gastroenterology 1995; 108: $252-75$.

3 Freeman BA, Crapo JD. Biology of disease. Free radicals and tissue injury. Lab Invest 1982; 47: 412-6.

4 Halliwell B. Reactive oxygen species in living systems: source, biochemistry, and role in human disease. $A m \mathcal{F}$ Med 1991; 91 (suppl3C): 14s-22s.

5 BeckmanJS,Beckman TW, ChenJ, MarshallPA, BreemanBA. Apparent hydroxyl radical production by peroxynitrite: implications for endothelial injury from nitric oxide and superoxide. Proc Natl Acad Sci USA 1990; 87: 1620-4.

6 Noronha-Dutra AA, Epperlein MM, Woolf N. Reaction of nitric oxide with hydrogen peroxide to produce potentially cyctotoxic singlet oxygen as a model for nitric oxide-mediated killing. FEBS Lett 1993; 1: 59-62.

7 Schmuckler DL, Ohta M, Kanai S, Sato Y, Kitani K. Hepatic injury induced by bile salts: correlation between biochemical and morphological events. Hepatology 1990; 12: $1216-21$

8 Güldütuna $S$, Zimmer $G$, Imhof $M$, Bhatti $S$, You $T$, Leuschner U. Molecular aspects of membrane stabilization by ursodeoxycholate. Gastroenterology 1993; 104: 1736-44.

9 DeRubertis FR, Craven PA. Relationship of bile salt stimulation of colonic epithelial phospholipid turnover and proliferative activity: role of activation of protein kinase C. Prev Med 1987; 16: 572-9.

10 Krähenbühl S, Talos C, Fischer S, Reichen J. Toxicity of bile acids on the electron transport chain of isolated rat liver mitochondria. Hepatology 1994; 19: 471-9. 
11 Spivey JR, Bronk SF, Gores GJ. Glycochenodeoxycholateinduced lethal hepatocellular injury in rat hepatocytes. Roles of ATP depletion and cytosolic free calcium. $\mathcal{F}$ Clin Invest 1993; 92: 17-24.

12 Sokol RI, Devereaux M, Khandwala R, O'Brien K. Evidence for involvement of oxygen free radicals in bile acid toxicity to isolated rat hepatocytes. Hepatology 1993; 17

13 Krähenbühl S, Talos C, Fisher S, Reichen J. Ursodeoxycholate decreases mitochondrial toxicity and membrane incorporation of lipophilic bile acids. Hepatology 1993; 18: 306A.

14 Krähenbühl S, Fischer S, Talos C, Reichen J. Ursodeoxycholate protects oxidative mitochondrial metabolism from bile acid toxicity: Dose-response study in isolated rat live mitochondria. Hepatology 1994; 20: 1595-601.

15 Hofmann AF. Pharmacology of ursodeoxycholic acid, an enterohepatic drug. Scand 7 Gastroenterol 1994; 29: 1-15.

16 Botla R, Spivey JR, Aguilar H, Bronk SF, Gores GJ. Ursodeoxycholate (UDCA) inhibits the mitochondrial membrane permeability transition induced by glycomembrane permeability transition induced by glyco-
chenodeoxycholate: A mechanism of UDCA cytochenodeoxycholate: A mechanism of UDCA
protection. F Pharmacol Exp Ther 1995; 272: 930-8.

17 Poupon R, Chrétien Y, Poupon RE, Ballet F, Calmus Y, Darnus F. Is ursodeoxycholic acid an effective treatmen for primary biliary cirrhosis. Lancet 1987; i: 834-6.

18 Leuschner U, Fischer H, Kurtz W. Ursodeoxycholic acid in primary biliary cirrhosis: results of a controlled doubleblind study. Gastroenterology 1989; 97: 1268-74.

19 Oka H, Toda G, Ikeda Y. A multi-center double-blind controlled trial of ursodeoxycholic acid for primary biliary cirrhosis. Gastroenterol fpn 1990; 25: 774-80

20 Poupon RE, Balkau B, Eschwege E, Poupon R. A multicenter controlled trial of ursodiol for the treatment of center controlled trial of ursodiol for the treatment of
primary biliary cirrhosis. $N$ Engl $7 \mathrm{Med} 1991$; 324: primary $1548-54$.

21 Heathcote EJ, Cauch-Dudek K, Walker V, Bailey RJ, Blendis LM, Ghent CN, et al. The Canadian multicente double-blind randomized controlled trial of ursodeoxycholic acid in primary biliary cirrhosis. Hepatology 1994; 19: 1149-56.

22 Lim AG, Northfield TC. Ursodeoxycholic acid and primary biliary cirrhosis. $B M F$ f 1994; 309: 491-2.

23 Lindor KD, Dickson ER, Baldus WP, Jorgensen RA Ludwig J, Murtaugh PA, et al. Ursodeoxycholic acid in the treatment of primary biliary cirrhosis. Gastroenterology 1994; 106: 1284-90.

24 Poupon RE, Poupon R, Balkau B, UDCA-PBC Study Group. Ursodiol for the long-term treatment of primary biliary cirrhosis. N Engl f Med 1994; 330: 1342-7.

25 Fuhrman B, Oiknine J, Aviram M. Iron induces lipid peroxidation in cultured macrophages, increases their ability to oxidatively modify LDL, and affects thei secretory properties. Atherosclerosis $1994 ; 111$ : $65-78$

26 Draper $\mathrm{HH}$, Hadley $\mathrm{M}$. Malondialdehyde determination as an index of lipid peroxidation. Methods Enzymol 1990 186: 421-31

27 Holley AE, Cheeseman KH. Measuring free radical reactions in vivo. Br Med Bull 1993; 49: 494-505.

28 Lowry OH, Rosebrough NJ, Farr AL, Randall RJ. Protein measurement with the folin phenol reagent. $f$ Biol Chem 1951; 193: 265-75.
29 Poupon R, Poupon RE. Ursodeoxycholic acid therapy of chronic cholestatic conditions in adults and children. Pharmacol Ther 1995; 66: 1-15.

30 Heuman DM. Quantitative estimation of the hydrophilichydrophobic balance of mixed bile salt solutions. F Lipid Res 1989; 30: 719-30.

31 Ostrow JD. Metabolism of bile salts in cholestasis in humans. In: Tavoloni N, Berk PD, eds. Hepatic transport and bile secretion: physiology and pathophysiology. New York: Raven Press, 1993: 673-712.

32 Stiehl A, Rudolph G, Raedsch R, Moller B, Hopf U, Lotterer $\mathrm{E}$, et al. Ursodeoxycholic acid-induced changes in plasma and urinary bile acids in patients with primary biliary cirrrhosis. Hepatology 1990; 12: 492-7.

33 Chrétien Y, Poupon R, Gherardt MF, Chazouilleres O, Labbe D, Myara A, Trivin F. Bile acid glycine and taurine conjugates in serum of patients with primary biliary cirrhosis: effect of ursodeoxycholic treatment. Gut 1989; 30: 1110-5.

34 Crosignani A Podda Mattezzati PM, Bertolini E Zuin M Watson D, Setchell KDR. Changes in bile acid composition in patients with primary biliary cirrhosis induced by ursodeoxycholic acid administration. Hepatology 1991; 14: 1000-7.

35 Leuschner $U$, Güldütuna $S$, Imhof $M$, Hübner $K$, Benjaminov A, Leuschner M. Effects of ursodeoxycholic acid after four to 12 years of therapy in early and late stages of primary biliary cirrhosis. $\mathcal{F}$ Hepatol 1994; 21 : 624-33.

36 Heuman DM, Mills AS, McCall J, Hylemon PB, Pandak WM, Vlahcevic ZR. Conjugates of ursodeoxycholate protect against cholestasis and hepatocellular necrosis caused by more hydrophobic bile salts. In vivo studies in the rat. Gastroenterology 1991; 100: 203-11.

37 Heuman DM. Hepatoprotective properties of ursodeoxycholic acid. Gastroenterology 1993; 104: 1865-70.

38 Jazrawi RP, De Caestecker JS, Goggin PM, Britten AJ, Joseph AEA, Maxwell JD, Northfield TC. Kinetics of hepatic bile acid handling in cholestatic liver disease: effect of ursodeoxycholic acid. Gastroenterology 1994; 106: 134-42.

39 Gurantz D, Schteingart CD, Hagey LR, Steinbach JH, Grotmol T, Hofmann AF. Hypercholeresis induced by unconjugated bile acid infusion correlates with recovery in bile of unconjugated bile acids. Hepatology 1991; 13: 540-50.

40 Anwer MS. Mechanism of bile acid-induced $\mathrm{HCO}_{3}^{-}$-rich hypercholeresis. An analysis based on quantitative acidhase chemistry. $\mathcal{F}$ Hepatol $1992 ; 14: 118-26$.

41 Elsing C, Sagesser H, Reichen J. Ursodeoxycholate-induced hypercholeresis in cirrhotic rats: further evidence for hypercholeresis in cirrhotic rats: further evidence for
cholehepatic shunting. Hepatology 1994; 20: 1048-54.

42 Yoshikawa M, Tsujii T, Matsumura K, Yamao J, Matsumura Y, Kubo R, Fukui H, Ishizaka S. Immunomodulatory effects of ursodeoxycholic acid on immue responses. Hepatology 1992; 16: 358-64.

43 Lacaille F, Paradis K. The immunosuppressive effect of ursodeoxycholic acid: a comparative in vivo study on human peripheral blood mononuclear cells. Hepatology 1993; 18: 165-72.

44 Heuman DM, Bajaj R. Ursodeoxycholate conjugates protect against disruption of cholesterol-rich membranes by bile salts. Gastroenterology 1994; 106: 1333-41. 